\title{
Food Safety Characterization of Food Enterprises for Inclusive Nutrition Sensitive Value Chain Development in Sub-Saharan Africa. A Case Study of the Orange Fleshed Sweet Potato Value Chain in Kenya
}

\author{
Beatrice Madeghe ${ }^{1,2}$ Mukani Moyo ${ }^{1 *}$ Lucy Mwaura $^{1} \quad$ Antonio Magnaghi $^{3} \quad$ Tawanda Muzhingi ${ }^{1,4}$ \\ 1.Food and Nutritional Evaluation Laboratory, International Potato Center (CIP), ILRI Campus, Old Naivasha \\ Road, P.O. Box 0010025171 - 00603 Nairobi, Kenya \\ 2.Food Science, Nutrition and Technology, University of Nairobi, P.O Box 29053-00625, Nairobi Kenya \\ 3.Euro-Ingredients Limited, Kikuyu, Box 954-00200, Nairobi, Kenya \\ 4.Department of Food, Bioprocessing and Nutrition Science, North Carolina State University, Raleigh, NC,
} 27695

\begin{abstract}
Food safety receives minimal attention and only captures national attention during foodborne disease outbreaks. The objective of this study was to explore the knowledge, attitudes and practices on food safety aspects related to Orange Fleshed Sweet potato (OFSP) along the food value chain in Kenya. A cross-sectional study was designed and investigated food safety knowledge, attitudes and practices (KAP) among the OFSP processors, traders, and consumers of street foods in Kenya. A socio-demographic questionnaire and KAP questionnaire were used as data collection instruments. The study included OFSP traders OFSP puree processors, large retailer's bakeries and consumers in Nairobi. The OFSP traders included were the suppliers of OFSP in the markets around Nairobi city. The OFSP consumers included the people who buy cooked OFSP from the street vendors in Nairobi city. Descriptive statistics such as percentage means and standard deviation were used to summarize the sociodemographic data and the knowledge, attitude, practices, and overall KAP. Pearson's correlation was used to establish an association of the three study components. Adjusted linear regression was used to assess the effect of food safety on knowledge, attitude, and practices. Knowledgeable, positive attitude and good practice on food safety were considered for mean scores above $80 \%$. Statistical significance was set at $\mathrm{p}<0.05$. The findings from the OFSP processors revealed a mean percentage score for knowledge, attitude, practices at 70.7\%, 93.5\%, and $90 \%$, respectively, with an overall mean score of $84.6 \%$. Lower education level was statistically significantly associated with food safety practices at $p=0.002$. Adjusted linear regression found a significant effect of food safety on knowledge at $\mathrm{p}<0.001$. Adjusted multiple regression revealed that age was statistically significantly associated with food safety knowledge, and food safety attitude (both at $\mathrm{p}<0.001$ ). Education level was significantly associated with food safety practices $(\mathrm{p}<0.001)$. Findings from OFSP traders revealed mean percentage scores for knowledge, attitude, practices at $63.1 \%, 74.4 \%$, and $64.7 \%$, respectively, with an overall mean score of $67.4 \%$. Pearson's correlation analysis revealed a strong positive correlation between food safety attitude and food safety practice $\mathrm{p}=0.015$. Similarly, a strong positive correlation between food safety practice and food safety knowledge was noted $(\mathrm{p}<0.001)$. Adjusted linear regression found that Food safety practice was significantly impacted by both knowledge and attitude $\mathrm{R} 2=0.578 \mathrm{~F}=49.6 \mathrm{p}=0.000$. Results from OFSP consumers revealed mean percentage scores for knowledge, attitude, practices at $66.2 \%, 87.3 \%$, and 91.6\%, respectively with an overall mean score of $81.7 \%$. Lower education level was statistically significantly associated with inappropriate practices among OFSP consumers $p=0.040$. Pearson's correlation analysis revealed a week positive correlation between food safety knowledge attitude and practice. : This study reveals a gap in the area of food safety knowledge, attitude, and practice along the OFSP value chain. The study highlights the need for policymakers to address and review the knowledge, attitude, and practices in the food industry, to raise food safety awareness campaigns and organize more targeted training along the food chains to reduce the foodborne disease burden.
\end{abstract}

Keywords: Food safety, Knowledge, attitude, practices, processor, traders, consumers

DOI: $10.7176 / \mathrm{FSQM} / 110-05$

Publication date:September $30^{\text {th }} 2021$

\section{Introduction}

Worldwide, foodborne illnesses are a growing and significant public health problem (Hossen et al., 2021). It presents a major concern on consumers and presents a barrier to smallholder farmers who wish to sell products in high-value domestic markets (Grace, 2015). An estimate of 600 million people, in the world, fall ill after eating contaminated food, and 420000 die every year, resulting in the loss of 33 million healthy life years (DALYs) (Todd, 2020); (WHO, 2015). In developing countries, the estimated burden of foodborne diseases is conservative and likely under-estimated (Yen et al., 2018). In Africa a conservative estimates of 137,000 deaths 
have been recorded and 91 million acute illnesses annually from foodborne hazards, with the heaviest burden of disease falling on children under five years of age (GFSP, 2019). In Kenya, foodborne diseases remain a problem, where approximately $70 \%$ of all episodes of diarrhea are attributable to ingestion of contaminated food and water (Oloo, 2011). Food safety usually receives minimal policy attention In many developing countries, and only captures national attention during foodborne disease outbreaks and other crises (WHO, 2015). Many countries have weak food safety systems in infrastructure, trained human resources, food safety culture, and enforceable regulations (Oloo, 2011). The continents of Africa, specifically Sub-Saharan Africa have been believed to have the highest rates of incidence and mortality associated with foodborne diseases (GFSP, 2019); (Le Nguyen et al., 2018). Through the food chain, food products may encounter many health hazards during their journey, right from the farm where they are grown, through the suppliers to processing to the consumers (Bendekovic et al., 2018). Foodborne hazards are biological, chemical, and physical contaminants with the potential to cause harm to human health, all of which have a significant interference to the development of socioeconomy worldwide (Le Nguyen et al., 2018). Biological hazards include viruses, bacteria, and parasites; chemical hazards include pollutants, heavy metals, and other toxins; physical includes objects that may cause harm include glass shards and nails (Grace, 2015). Unhygienic practices during food preparation, handling, and storage create conditions that allow the proliferation and transmission of disease-causing organisms such as bacteria, viruses, and other foodborne pathogens (Jubayer et al., 2020). Unsafe food undermines food and nutritional security, human development, the broader food economy, and international trade (WHO, 2015).

Worldwide, it is recognized that the application of the HACCP principles to food production and preparation has clear benefits and the potential of enhancing food safety and preventing many cases of foodborne diseases (WHO, 1999). Nevertheless, despite wide dissemination and support of these principles, successful HACCP implementation has been limited (Marais et al., 2007). Growing food in chemically contaminated soils can result in the uptake of chemicals. In Kenya, processed foods constitute $75 \%$ of the diets in the urban and $25 \%$ of the diets in the rural areas, the informal sector in the food industry comprises small and medium-sized enterprises and food vendors, who supply at least $80 \%$ of the food products to domestic markets, under rudimentary hygiene controls (Oloo, 2011). Farmers must apply Good Agricultural Practices (GAP). Sellers of commodities/raw materials at the local or international level must apply Good Distribution Practices (GDP), and manufacturers must apply Good Manufacturing Practices (GMP). These practices are generally Good Hygiene Practices (GHP) fundamental to Hazard Analysis and Critical Control Points (HACCP) standards (WHO, 1999). Informal food markets in developing countries has been a significant challenge to the application of HACCP; moreover, there is minimal awareness and application of basic hygiene practices among food handlers and consumers (Oloo, 2011). Knowledge, attitude, and practices (KAP) about food safety are essential because inadequate knowledge, poor attitude, and poor sanitation practices severely endanger food safety applications in food value chain (WHO, 2015). Therefore, with a backdrop of this understanding, this paper aims to explore about food safety knowledge, attitude, and practices (KAP) among OFSP farmers, traders, processors, and consumers using a case study of orange-fleshed sweet potatoes along the food vale chai in Kenya

\section{2. Methods}

\subsection{Study design and area}

This descriptive cross-sectional study investigated the knowledge attitude and practice (KAP) among the Orange Fleshed Sweet Potatoes (OFSP) Processors, traders, and consumers in Kenya. Included in the study were the OFSP processors in Naivas supermarket bakeries and puree processors in Organi limited in Bungoma. OFSP traders involved the distributers of OFSP in the market around Nairobi city county in Muthuruwa, Malikiti, Kangemi, and Makina, Kibera markets in Kibera. The OFSP consumer involved the consumers who buy OFSP from the street vendors in Nairobi city around Kibera, Kenyata market, and Makina. This descriptive crosssectional study was conducted during February and March 2021. The sampling method was purposive convenience sampling, where 32 OFSP processors, 75 OFSP traders, and 50 OFSP consumers were recruited in the study.

\subsection{Data collections:}

By mean of the questionnaire administered interviews, the data was collected; the first part of the questionnaire was the Socio-demographics questionnaire in which the participants included the OFSP traders, OFSP processors, and OFSP consumers who provided data on socio-demographic characteristics, including age, gender, education level, occupation, and occupation. The KAP questionnaire:- The knowledge, attitude, and practice of OFSP traders, processors and consumers were assessed using structured KAP questionnaire designed based on HACCP Principles developed on previous similar studies by (Malavi 2017); (Jubayer et al., 2020); (Hossen et al., 2021); (Fariba et al., 2018). The KAP questionnaire was divided into three sections: the knowledge, attitude and practice to understand food safety awareness and compliance of good practices in processing distribution and consumption. The first section covered food safety knowledge on personal hygiene and foodborne illnesses, food 
contamination. The response choices were Yes, No, and Do not Know; the second part of the question covered food safety attitude among OFSP processors, traders, and consumers attitude towards food safety on a 5-point Likert-type scale with options being Strongly agree, Agree, Do not Know, Disagree and Strongly Disagree. The third section of the questionnaire covered the food safety practice among OFSP processors, traders, and consumers with Always, Sometimes, Rarely, and Never. All questionnaires were administered in face-to-face interviews; and the respondents were explained that and the information was for research purposes, and each respondent signed a consent form prior to participating.

\subsection{Data analysis}

The data collected were checked for completeness, then data entry and cleaning were done. The data were analyzed using SPSS for Windows version 22. Descriptive statistics such as percentage means and standard deviation were used to summarize the socio-demographic data. For food safety knowledge, responses were categorized as either knowledgeable or not knowledgeable. Each correct answer was awarded one point, while the incorrect response was awarded zero points. In the food safety attitude section, responses were categorized as positive and negative attitudes. Each positive attitude response was awarded one point and zero points for a negative attitude. Similarly, for practice section was categorized as appropriate hygiene practice and inappropriate hygiene practice; one point was awarded for each appropriate hygiene practice while unhygienic practice was not awarded any point. All correct scores for food safety knowledge, attitude, and practices for each respondent were summed up and calculated as a percentage. Frequencies and descriptive statistics were used to summarize scores for each question, knowledge, attitude, practices, and overall KAP. The mean scores for knowledge, attitude, and practices among respondents in different age groups, education level, and occupation were compared by one-way ANOVA. Pearson's correlation was used to establish an association of the three study components (KAP). Adjusted linear regression was used to assess the effect of food safety knowledge and attitude on practices. Multiple regressions were used to assess the effect of socio-demographic factors on food safety knowledge, attitude, and practices. Knowledgeable, positive attitude and good practice on food safety were considered for mean scores above $80 \%$. Statistical significance was set at $\mathrm{p}<0.05$.

\section{Results:}

\subsection{KAP food safety among OFSP processors}

\subsubsection{Sociodemographic characteristics}

Out of 32 respondents recruited in the study, $50 \%$ were male, while $50 \%$ were female. About $78 \%$ of all OFSP processors were within the age group 25 years and above. The majority of the respondents (43.8\% and $46.9 \%)$ had attained secondary education $43.8 \%$, and $46.9 \%$ tertiary education, only $9.4 \%$ had primary education. About $43.8 \%$ of OFSP processors were working as full-time waged employees in the processing industry. See Table 1.

Table 1: Social demographic characteristics of OFSP processors $(\mathrm{N}=32)$

\begin{tabular}{llll}
\hline $\begin{array}{l}\text { Social } \\
\text { Variables }\end{array}$ & demographic & Frequency (n) & Percentage (\%) \\
\hline Gender & Male & 16 & 50.0 \\
& Female & 16 & 50.0 \\
\hline Age (Years) & $18-24$ & 7 & 21.9 \\
& $25-29$ & 13 & 40.6 \\
& $30-34$ & 7 & 21.9 \\
& $35-39$ & 2 & 6.3 \\
& 40 and above & 3 & 9.4 \\
\hline Education level & Primary & 3 & 9.4 \\
& Secondary & 14 & 43.8 \\
& Tertiary & 15 & 46.9 \\
\hline Main occupation & Farmer & 6 & 18.8 \\
& Full time waged employed & 14 & 43.8 \\
& Part time wage employed & 8 & 25.0 \\
& Self employed & 1 & 3.1 \\
& Others & 3 & 9.4 \\
\hline
\end{tabular}

\subsubsection{Food Safety Knowledge, Attitude, Practices and (KAP) overall, among OFSP processors}

The results revealed that OFSP processors had a mean percentage score for knowledge, attitude, practices at $70.7 \%, 93.5 \%$, and $90 \%$, respectively, with an overall mean score of $84.6 \%$. The mean percentage score on Knowledge was below the cut-off of $80 \%$ indicating need to improve knowledge among the processors. The food safety attitude of the OFSP was excellent at $93.5 \%$ and food safety practices were very good at $84.6 \%$. The mean percentage scores for knowledge, attitude, and practice among OFSP processors and overall KAP see figure 1 . 


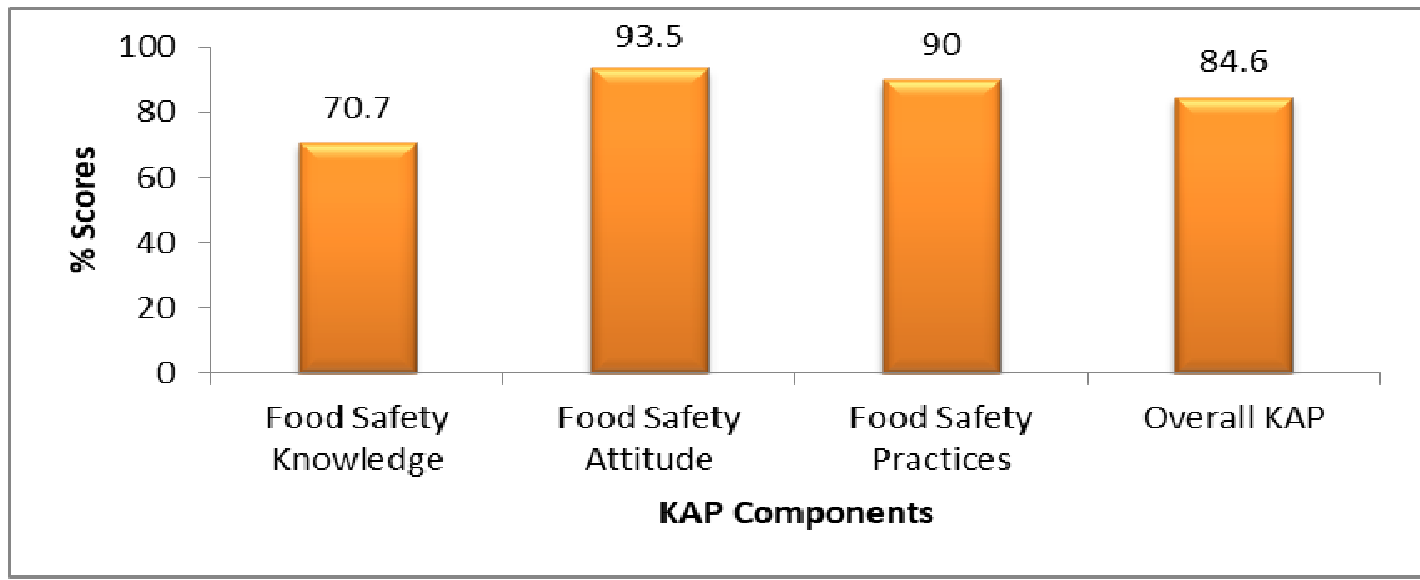

Figure 1: The mean percentage scores for knowledge, attitude, practice among OFSP processors and overall KAP

3.1.3 Association between sociodemographic characteristics and overall KAP among OFSP processors

When socio-demographic characteristics were compared with KAP overall, the only statistically significant factor associated with food safety KAP overall was the education which was statistically significantly associated with food safety KAP $\mathrm{p}=0.002$. Other factors were not significantly associated with KAP overall. See table 2 .

Table 2: Mean scores: Food Safety Knowledge, Attitude, Practices and Overall KAP of OFSP processors as per demographic characteristics by ANOVA and t-Test

\begin{tabular}{|c|c|c|c|c|c|c|c|c|c|}
\hline \multirow{2}{*}{$\begin{array}{l}\text { Demographic } \\
\text { variable }\end{array}$} & & \multirow[t]{2}{*}{$\mathrm{N}$} & \multicolumn{2}{|l|}{ Knowledge } & \multicolumn{2}{|l|}{ Attitude } & \multicolumn{3}{|l|}{ Practices } \\
\hline & & & Mean \pm SD & $\begin{array}{l}\mathrm{p}- \\
\text { value }\end{array}$ & Mean \pm SD & $\begin{array}{l}\mathrm{p}- \\
\text { value }\end{array}$ & Mean \pm SD & $\begin{array}{l}\mathrm{p}- \\
\text { value }\end{array}$ & \\
\hline \multirow[t]{2}{*}{ Gender } & Male & 16 & $70.5 \pm 8.3$ & 1.00 & $92.9 \pm 10.7$ & 0.693 & $89.1 \pm 6.3$ & 0.495 & \\
\hline & Female & 16 & $70.5 \pm 6.9$ & & $94.1 \pm 6.3$ & & $90.8 \pm 7.2$ & & \\
\hline \multirow[t]{5}{*}{ Age (Years) } & $18-24$ & 7 & $70.2 \pm 6.4$ & & $94.2 \pm 1.7$ & & $92.3 \pm 2.5$ & & \\
\hline & $25-29$ & 13 & $70.1 \pm 7.0$ & & $95.3 \pm 6.8$ & 0.391 & $88.2 \pm 8.6$ & & \\
\hline & $30-34$ & 7 & $73.7 \pm 11.0$ & 0.838 & $88.5 \pm 14.7$ & & $90.4 \pm 6.5$ & 0.779 & \\
\hline & $35-39$ & 2 & $68.0 \pm 5.6$ & & $100.0 \pm 0$ & & $90.0 \pm 4.7$ & & \\
\hline & $40+$ & 3 & $69 . \pm 6.1$ & & $93.5 \pm 8.7$ & & $91.1 \pm 7.7$ & & \\
\hline \multirow{3}{*}{$\begin{array}{l}\text { Education } \\
\text { level }\end{array}$} & Primary & 3 & $78 \pm 2.3$ & & $97.7 \pm 3.8$ & & $100.0 \pm 0.0$ & & \\
\hline & Secondary & 14 & $71.4 \pm 4.9$ & 0.093 & $93.8 \pm 11.5$ & 0.634 & $86.6 \pm 6.1$ & 0.002 & \\
\hline & Tertiary & 15 & $68.5 \pm 9.1$ & & $92 \pm 6.1$ & & $91.4 \pm 6.0$ & & \\
\hline \multirow{5}{*}{$\begin{array}{l}\text { Main } \\
\text { Occupation }\end{array}$} & Farmer & 6 & $71.3 \pm 6.4$ & & $95.5 \pm 5.4$ & & $91.1 \pm 10.0$ & & \\
\hline & $\begin{array}{l}\text { Full time } \\
\text { wage } \\
\text { employed }\end{array}$ & 14 & $68.2 \pm 5.9$ & & $90.0 \pm 11.0$ & & $88.1 \pm 5.9$ & & \\
\hline & $\begin{array}{l}\text { Part time } \\
\text { wage } \\
\text { employed }\end{array}$ & 8 & $73.0 \pm 10.1$ & & $96.6 \pm 5.0$ & & $92.5 \pm 6.6$ & 0.639 & \\
\hline & $\begin{array}{l}\text { Self } \\
\text { employed }\end{array}$ & 1 & 72.0 & & $100.0 \pm 0$ & & 93.3 & & \\
\hline & Others & 3 & $74.6 \pm 10.0$ & & $95.5 \pm 7.7$ & & $88.9 \pm 3.8$ & & \\
\hline Mean & & & $71.3 \pm 2.6$ & & $94.6 \pm 3.2$ & & $90.9 \pm 3.1$ & & $85.6 \pm 12.4$ \\
\hline
\end{tabular}

\subsubsection{Food Safety Knowledge among OFSP Processors}

The majority of the processors, $90.6 \%$, were knowledgeable about OFSP as the products with high vitamin A content. They knew that consuming orange-fleshed sweet potatoes can reduce nutritional deficiencies. All processors $100 \%$, knew that food safety is an important aspect in producing quality and nutritious food, and Hygiene rules in the processing is everyone's responsibilities. However, $34.4 \%$ of the processors were did not know that microbes are in the skin, nose, and mouth of healthy food handlers. About $68 \%$ of the respondents did not know that working without protective clothing is not bad and is sometimes allowed in a food factory. About $84.4 \%$ did not know that cleaning chemicals and food ingredients should not be kept together in one store. See table 3. 
Table 3: Food Safety Knowledge responses by OFSP Processors $(\mathrm{N}=32)$

\section{Food Safety questions}

1 Orange fleshed sweet potatoes are one of product with high vitamin A content

2 Consuming orange fleshed sweet potatoes can reduce nutritional deficiencies in children and old people

3 Food safety is very important aspect in producing quality and nutritious food

4 Hygiene rules in processing are everyone's responsibilities

$\begin{array}{ll}5 & \text { Food borne diseases are transmitted by food / water contamination }\end{array}$

6 Coughing and sneezing can cause food contamination

7 Droppings, torn packages/gnawed packages indicate pest infestation

8 During infectious disease of the skin, it is necessary to take leave from work

9 Only sick people carry bacteria which causes food poisoning

10 Microbes are in the skin, nose and mouth of healthy food handlers

11 Typhoid fever can be transmitted by food

12 Food production staff should have health check-ups every two years

13 Washing hands before work reduces the risks of food contamination

14 Working without protective clothing is sometimes allowed in a food factory

15 Using gloves while handling food reduces the risk of food contamination

16 Eating and drinking in the work place increases the risk of food contamination

17 Proper cleaning and sanitization of equipment reduces the risks of food contamination

18 Working with jewelry is allowed in processing plant

19 Clean is the same as sanitize

20 Cleaning chemicals and food ingredients should be kept together in one store

21 Cleaning of equipment should always be done at the end of processing

22 Contaminated foods can be detected by changes in color, odor or taste

23 Raw food and processed food should be kept separate

24 Temperature control is important in storage and processing of safe foods

\subsubsection{Food Safety attitude among OFSP Processors}

Generally, most OFSP processors had a positive attitude toward food safety. All processors $100 \%$ are optimistic that safe food handling is their job responsibility and are optimistic that learning more about food safety is important to them. However, $25 \%$ of the processors are believe that well-processed foods are free from contamination, and $25.5 \%$ of the respondents believe that it is not necessary to have medical examinations because they are healthy. See table 4.

Table 4.Food Safety Attitude responses by OFSP Processors $(\mathrm{N}=32)$

\begin{tabular}{|l|l|l|l|}
\hline & Statement on Food Safety Attitude & $\begin{array}{l}\text { Positive } \\
\text { Attitude (\%) }\end{array}$ & $\begin{array}{l}\text { Negative } \\
\text { Attitude (\%) }\end{array}$ \\
\hline 1 & Safe food handling is my job responsibilities & 100.0 & 0.0 \\
\hline 2 & Learning more about food safety is important to me & 100.0 & 0.0 \\
\hline 3 & I believe that how i handle food relates to food safety & 96.9 & 3.1 \\
\hline 4 & Well processed foods are free from contamination & 75.0 & 25.0 \\
\hline 5 & Proper hand washing can prevent food-borne diseases & 93.8 & 6.3 \\
\hline 6 & Raw and processed food should be stored separately & 100.0 & 0.0 \\
\hline 7 & It is necessary to check the temperature of refrigerators/freezers periodically & 96.9 & 3.1 \\
\hline 8 & The health status of workers should be evaluated before employment & 96.9 & 3.1 \\
\hline 9 & $\begin{array}{l}\text { Wearing a mask is an important practice to reduce the risks of food } \\
\text { contamination }\end{array}$ & 87.5 & 12.5 \\
\hline 10 & $\begin{array}{l}\text { Wearing gloves is an important practice to reduce the risk of food } \\
\text { contamination }\end{array}$ & 96.9 & 3.1 \\
\hline 11 & $\begin{array}{l}\text { Food handlers who have abrasions or cuts on their hands should not touch } \\
\text { food without gloves }\end{array}$ & 96.9 & 3.1 \\
\hline 12 & It is unnecessary to have medical examination because am healthy & 75.0 & 25.5 \\
\hline 13 & You can keep working with exposed body cut or hand injury & 96.9 & 3.1 \\
\hline 14 & PPE / Apron can be used to clean dirty hands & 90.6 & 9.4 \\
\hline 15 & I can chew / smoke while working & 100.0 & 0 \\
\hline
\end{tabular}




\subsubsection{Food Safety practice among OFSP Processors}

Results reveal that OFSP processors understand the principles of good manufacturing practice. All OFSP Processors $100 \%$ practice washing hands before and after work and they use some kind of detergents such as liquid soap to wash hands, most of them they use gloves when touching the food and clean their working area before preparation. However, about $30 \%$ of the processors do not wash their hands after using gloves. The implication of this may lead to cross contaminations to food. About $15.6 \%$ of the processors do not check the temperature of the insides of your food product. See table 5.

Table 5: Frequency of scores on Food safety Practices

\begin{tabular}{|l|l|l|l|}
\hline & Food safety Practices questions & $\begin{array}{l}\text { Appropriate practice } \\
(\mathbf{\%})\end{array}$ & $\begin{array}{l}\text { Inappropriate practice } \\
(\mathbf{\%})\end{array}$ \\
\hline $\mathbf{1}$ & Do you wash your hand before / after working & 100.0 & 0.0 \\
\hline $\mathbf{2}$ & Do you use bar or liquid soap to wash hands & 100.0 & 0.0 \\
\hline $\mathbf{3}$ & Do you dry your hands with a disposable / paper towel & 96.9 & 3.1 \\
\hline $\mathbf{4}$ & Do you wear hats or headgear & 90.6 & 9.4 \\
\hline $\mathbf{5}$ & Do you check the temperature of insides of your food & 84.4 & 15.6 \\
\hline $\mathbf{6}$ & $\begin{array}{l}\text { Do you wash your hands with soap after visiting the } \\
\text { washrooms }\end{array}$ & 0.0 \\
\hline $\mathbf{7}$ & $\begin{array}{l}\text { Do you use gloves when you touch or distribute } \\
\text { unwrapped foods }\end{array}$ & 100.0 & 0.0 \\
\hline $\mathbf{8}$ & Do you wash your hands before wearing gloves & 93.8 & 6.3 \\
\hline $\mathbf{9}$ & Do you wash your hands after using gloves & 78.1 & 21.9 \\
\hline $\mathbf{1 0}$ & Do you wear nail polish when handling food & 87.5 & 12.5 \\
\hline $\mathbf{1 1}$ & Do you wear an apron while working & 93.8 & 6.3 \\
\hline $\mathbf{1 2}$ & $\begin{array}{l}\text { Do you clean your working area before food } \\
\text { preparation }\end{array}$ & 100.0 & 0.0 \\
\hline $\mathbf{1 3}$ & $\begin{array}{l}\text { Do you check shelf life of foods / ingredients at the } \\
\text { time of delivery }\end{array}$ & 100.0 & 0.0 \\
\hline $\mathbf{1 4}$ & $\begin{array}{l}\text { Do you check the packing integrity of foods at the time } \\
\text { of dispatch / delivery }\end{array}$ & 100.0 & 0.0 \\
\hline $\mathbf{1 5}$ & $\begin{array}{l}\text { Do you properly clean the food storage area before } \\
\text { storing new products }\end{array}$ & 100.0 \\
\hline $\mathbf{3}$ & 0.0 \\
\hline
\end{tabular}

\subsubsection{The correlation among Knowledge, Attitude and Practices of OFSP Processors}

The result reveals a weak positive correlation between food safety knowledge and attitude, there was a weak correlation between Attitude and practice, and a weak correlation between practices and knowledge. See table 6 .

Table 6: Correlation among Knowledge, Attitude and Practices of OFSP Processors

Level

Knowledge - Attitude Pearson correlation (r)

Attitude - Practice

0.304

Practices - Knowledge

0.134

p-values

0.091

0.269

0.134

0.137

*Correlation significant at 0.05 level ( 2 tailed) but none is significant $\mathrm{p}>0.05$

Adjusted linear regression assessed the effect of food safety knowledge and attitude on food safety practices; results revealed a significant association between Knowledge and practice $p<0.001$. There was no significant effect on food safety attitude and practice. See table 7 .

Table 7: Adjusted linear regression assessing the effect of food safety knowledge and attitude on food safety practices

\begin{tabular}{llll} 
Variables & Coefficient & Std. Error & p-value \\
\hline Knowledge & 0.137 & 0.101 & $0.000^{*}$ \\
Attitude & 0.044 & 0.141 & 0.191 \\
& & $\mathrm{R}^{2=} 0.062, \mathrm{~F}=1.178, \mathrm{p}=0.322$ & \\
\hline
\end{tabular}

*Variables significant at 0.05 (2 tailed)

Moreover, adjusted multiple regression assessed the effect of age and education level on food safety knowledge, attitude and practices, results revealed that Age was statistically significantly associated with food safety knowledge $\mathrm{p}<0.001$, and food safety attitude $\mathrm{p}<0.001$. Education level was significantly associated with food safety practices $\mathrm{p}<0.001$. See table 8 . 
Table 8: Adjusted multiple regression assessing the effect of age and education level on safety on knowledge, attitude and practices

\begin{tabular}{|c|c|c|c|c|c|c|c|c|c|}
\hline & \multicolumn{3}{|c|}{ Food safety knowledge } & \multicolumn{3}{|c|}{ Food Safety Attitude } & \multicolumn{3}{|c|}{ Food Safety Practices } \\
\hline Variables & Coefficient & Std. Error & $\begin{array}{l}\mathrm{p}- \\
\text { value }\end{array}$ & Coefficient & $\begin{array}{l}\text { Std. } \\
\text { Error }\end{array}$ & $\begin{array}{l}\mathrm{p}- \\
\text { value }\end{array}$ & Coefficient & $\begin{array}{l}\text { Std. } \\
\text { Error }\end{array}$ & $\begin{array}{l}\mathrm{p}- \\
\text { value }\end{array}$ \\
\hline Age & 0.001 & 0.129 & 0.00 & 0.112 & 0.534 & 0.00 & 0.131 & 0.418 & 0.942 \\
\hline $\begin{array}{l}\text { Education } \\
\text { level }\end{array}$ & 0.368 & 0.486 & 0.657 & 0.543 & 0.123 & 0.540 & 0.577 & 0.230 & 0.001 \\
\hline & & $\begin{array}{l}\mathrm{R}^{2}=0.107, \mathrm{~F}=4.7 \\
\mathrm{p}=0.00\end{array}$ & & $\begin{array}{l}\mathrm{R}^{2}=0.006 \\
\mathrm{~F}=0.082 \\
\mathrm{P}=0.371\end{array}$ & & & $\begin{array}{l}\mathrm{R}^{2}=0.033 \\
\mathrm{~F}=0.005 \\
\mathrm{P}=0.982\end{array}$ & & \\
\hline
\end{tabular}

\subsection{Orange Fleshed Sweet potato (OFSP) Traders in Nairobi Kenya}

\subsubsection{Social Demographic Characteristics}

A total of 75 sweet potato traders were recruited in the study, about $52 \%$ were males, and $48 \%$ were females, with 14.7\% OFSP respondents with an age range between 18-24 14.7\% and 48\% had an age range between $25-$ 34 and the rest had an age range between $35-54$. Only $26.7 \%$ had a primary level education, but the rest had secondary level $62.7 \%$ and tertiary level $10.7 \%$. The main occupation was the business of selling potatoes. See table 9.

Table 9: Social Demographic Characteristics of OFSP Traders $(\mathbf{N}=75)$

Social demographic Variables

\begin{tabular}{llll} 
Social demographic Variables & & Frequency $(\mathrm{n})$ & Percentage $(\%)$ \\
\hline Gender & Males & 39 & 52.0 \\
& Females & 36 & 48 \\
\hline Age (Years) & $18-24$ & 11 & 14.7 \\
& $25-34$ & 36 & 48.0 \\
& $35-44$ & 19 & 25.3 \\
Education level & $45-54$ & 9 & 12.0 \\
& Primary & 20 & 26.7 \\
& Secondary & 47 & 62.7 \\
& Tertiary & 8 & 10.7 \\
\hline Main occupation & & & 100.0
\end{tabular}

\subsubsection{Food Safety Knowledge, Attitude and Practices (KAP) overall, among OFSP Traders}

This study revealed a mean percentage scores OFSP food safety of knowledge at $63.1 \%$, which is very low; this could be contributed by many factors, including lack of awareness about food safety transportation regulation and lack of enforcement of the laws available transportation. About $74.4 \%$ of OFSP traders had a positive food safety attitude which is below the cut-off point. The mean percentage scores of food safety practice was at $64.7 \%$ which is below the cut-off point. The overall a mean percentage scores food safety KAP among OFSP traders was 67.4 , which is below the cut-off point of $80 \%$ mean score, these results reveal a need to enforce KAP among the traders to improve food safety practices. The mean percentage scores For Safe Food Safety Knowledge, Attitude and Practice of OFSP Traders See figure 2.

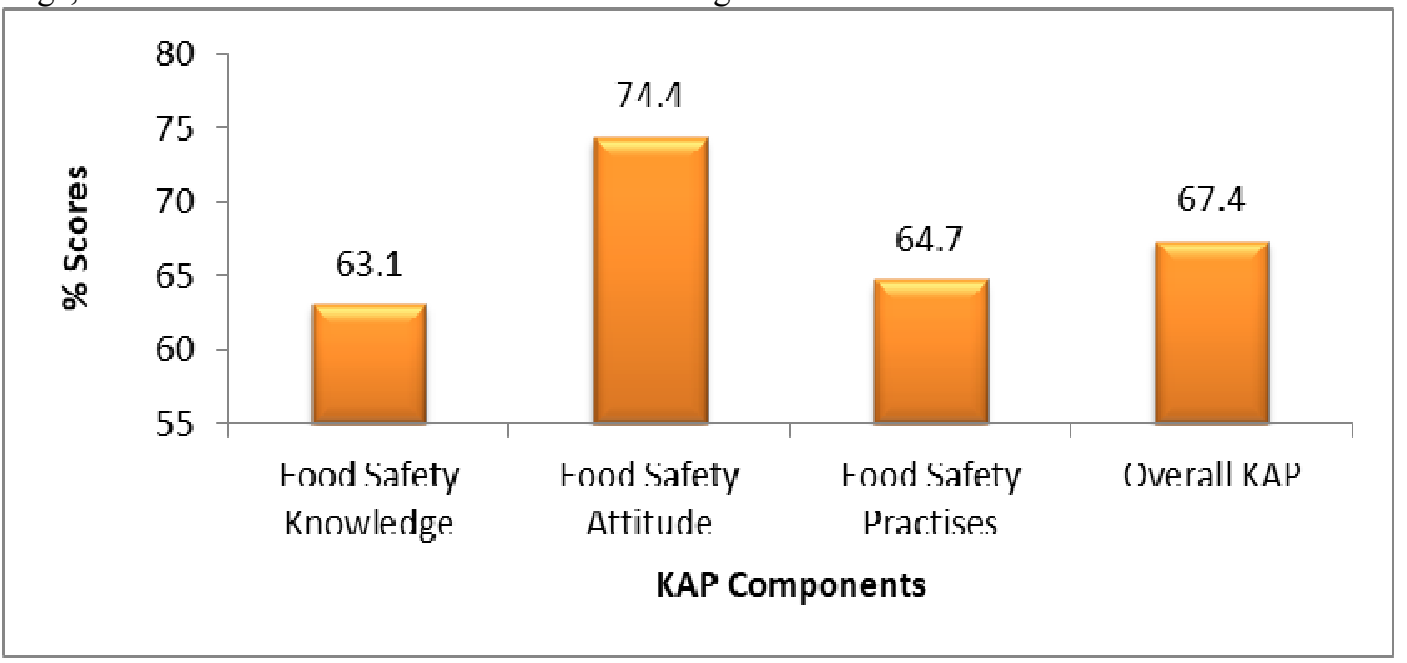

Figure 2: Mean percentage scores For Safe Food Safety Knowledge, Attitude and Practice of OFSP Traders 
3.2.3 Association between sociodemographic characteristics and Food safety KAP among OFSP traders Socio-demographic characteristics were compared with the OFSP traders overall food safety KAP; results reveled that there was statistically significant association between education and food safety KAP $p=0.049$, other demographic factors did not have any statistically significant association with food safety KAP overall. See table 10

Table 10: Means Scores: Food Safety Knowledge, Attitude, Practices and Overall KAP of OFSP Traders as per demographic characteristics by ANOVA and Test

\begin{tabular}{|c|c|c|c|c|c|c|c|c|}
\hline \multirow{2}{*}{$\begin{array}{l}\text { Demographic } \\
\text { variable }\end{array}$} & & \multirow[t]{2}{*}{$\mathbf{N}$} & \multicolumn{2}{|c|}{ Knowledge } & \multicolumn{2}{|l|}{ Attitude } & \multicolumn{2}{|l|}{ Practices } \\
\hline & & & Mean \pm SD & $\begin{array}{l}\mathrm{p}- \\
\text { value }\end{array}$ & Mean \pm SD & $\begin{array}{l}\mathrm{p}- \\
\text { value }\end{array}$ & Mean \pm SD & $\begin{array}{l}\mathrm{p}- \\
\text { value }\end{array}$ \\
\hline \multirow[t]{2}{*}{ Gender } & Males & 39 & $64.1 \pm 14.8$ & 0.530 & $75.6 \pm 21.4$ & 0.631 & $67.8 \pm 18.0$ & 0.235 \\
\hline & Females & 36 & $61.9 \pm 14.7$ & & $73.1 \pm 23.4$ & & $62.0 \pm 18.3$ & \\
\hline \multirow[t]{4}{*}{ Age (Years) } & $18-24$ & 11 & $60.9 \pm 13.7$ & & $76.5 \pm 30.7$ & & $67.5 \pm 22.2$ & \\
\hline & $25-34$ & 36 & $64.8 \pm 16.0$ & 0.581 & $77.3 \pm 18.1$ & 0.584 & $65.9 \pm 20.3$ & 0.793 \\
\hline & $35-44$ & 19 & $59.7 \pm 13.2$ & & $71.1 \pm 23.5$ & & $62.0 \pm 13.4$ & \\
\hline & $45-54$ & 9 & $65.5 \pm 13.8$ & & $67.6 \pm 24.8$ & & $61.6 \pm 14.7$ & \\
\hline \multicolumn{9}{|l|}{$\begin{array}{l}\text { Education } \\
\text { level }\end{array}$} \\
\hline Primary & & 20 & $61.0 \pm 15.8$ & & $79.5 \pm 24.5$ & & $60.9 \pm 16.7$ & \\
\hline Secondary & & 47 & $61.9 \pm 13.7$ & 0.049 & $71.9 \pm 21.7$ & 0.438 & $64.3 \pm 18.0$ & 0.146 \\
\hline Tertiary & & 8 & $75.0 \pm 14.7$ & & $76.0 \pm 19.6$ & & $75.9 \pm 20.9$ & \\
\hline Mean & & & $63.8 \pm 4.6$ & & $74.3 \pm 3.7$ & & $65.3 \pm 4.7$ & \\
\hline
\end{tabular}

\subsubsection{Food Safety Knowledge among OFSP Traders in Nairobi Kenya}

The results reveal that OFSP traders did not have sufficient knowledge about transportation. Although about $85.3 \%$ of OFSP traders know the importance of food safety and have heard about food bone illnesses, a high percent $37.3 \%$ of OFSP traders did not know what causes foodborne illnesses. About $45 \%$ of OFSP did not know any transport regulations, and $52 \%$ do not follow any transportation regulations available. About $70 \%$ of the traders do not control temperature while transporting their products. See table11.

Table 11: Food safety knowledge responses by OFSP Traders $(N=75)$

\begin{tabular}{llcc}
\hline & Food Safety Questions & $\begin{array}{l}\text { With } \\
\text { Knowledge } \\
\text { (\%) }\end{array}$ & $\begin{array}{l}\text { Without } \\
\text { Knowledge } \\
\text { (\%) }\end{array}$ \\
\hline 1 & Do you know/have you heard about food safety? & 84.0 & 16.0 \\
2 & Do you know about food bone/food poisoning? & 85.3 & 14.7 \\
3 & Do you know what causes food bone illness/food poisoning? & 62.7 & 37.3 \\
4 & Do you have any challenges in transporting this product OFSP & 74.7 & 25.3 \\
5 & Do you have transport regulations? & 54.7 & 45.3 \\
6 & Do you follow those regulations? & 48.0 & 52.0 \\
7 & Do you shelter your product OFSP when transporting? & 66.7 & 33.3 \\
8 & Do you clean your trucks and vehicles before and after loading? & 58.7 & 41.3 \\
9 & Do you have any storage facilities? & 49.3 & 50.7 \\
10 & Are your storage facilities cleaned and maintained? & 56.0 & 44.0 \\
11 & Do you have policy/procedures which specify handling/disposition & 53.3 & 46.7 \\
& products? & & 70.7 \\
12 & Do you control temperature while transporting your product? & 29.3 & 73.3 \\
13 & Do you maintain suitable temperature in your storage facilities? & 26.7 & 22.7 \\
14 & Do you apply hygiene practices when transporting your product? & 77.3 & 21.3 \\
15 & Do you accept products that are exposed to contamination? & 78.7 & 18.7 \\
16 & Do you have food disposal place for rotten food products? & 81.3 & 21.3 \\
17 & Do you practice hygiene during packing the food product? & 78.7 & 65.3 \\
18 & Do you use First in First out method of inventory? & 94.7 & 34.7 \\
19 & Do you look for damaged and spoiled products? & 93.3 & 6.3 \\
20 & Do you discard all expired food? & & 6.7 \\
\hline
\end{tabular}

\subsubsection{Food Safety attitude responses among OFSP traders in Nairobi Kenya}

About $96 \%$ of OFSP traders have a positive attitude about food safety and know that safe product handling will prevent food contamination. However, about half of OFSP traders $49.3 \%$ did not believe that washing hands before and after handling products can prevent cross-contamination. Also, about $29 \%$ of the OFSP traders did not believe that produce need be shielded or covered during transportation to prevent products from 
contamination. See table12.

Table 12: Table 4.Food Safety Attitude responses by OFSP Processors $(N=75)$

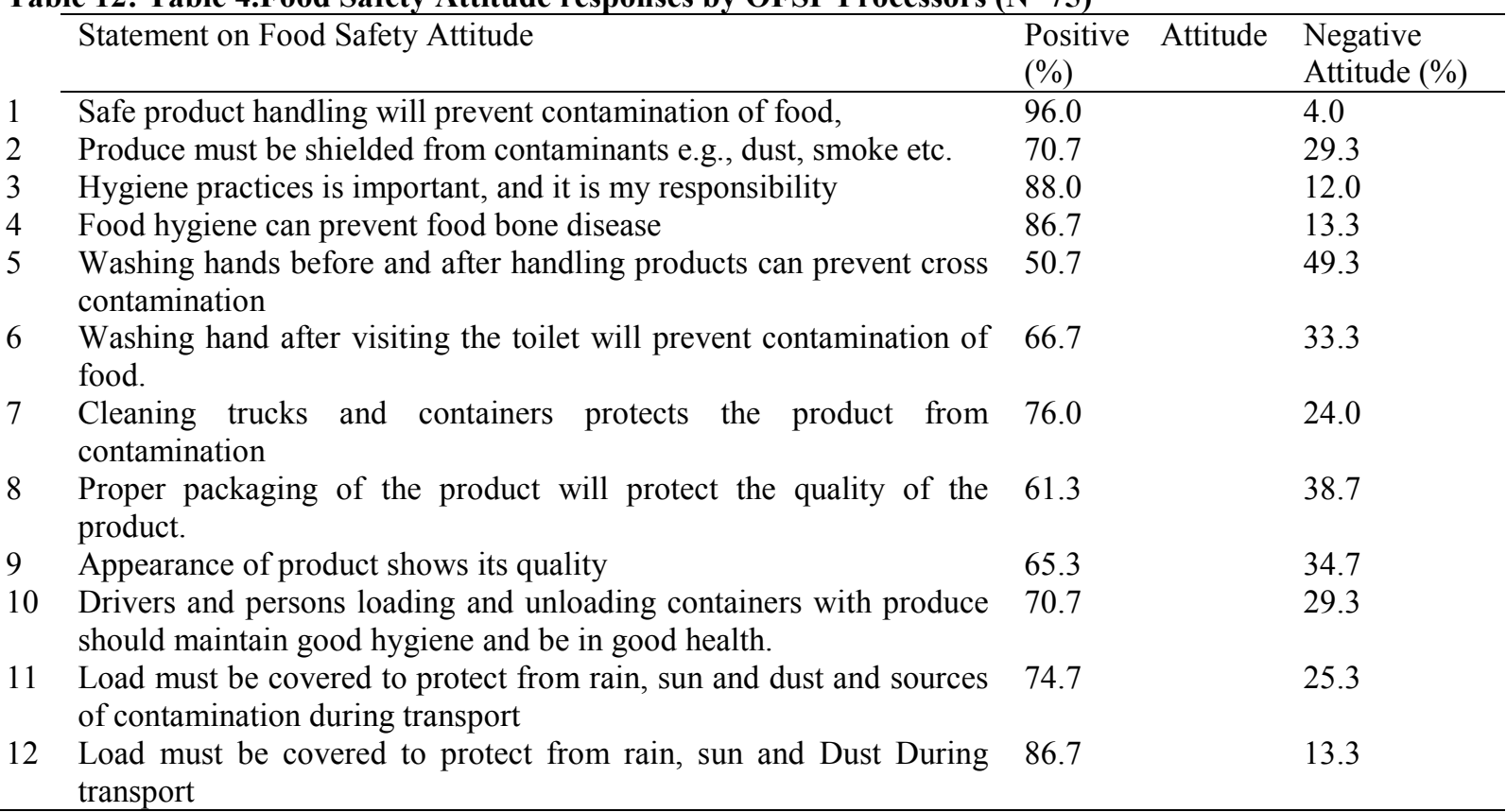

\subsubsection{Food Safety practices among OFSP traders in Nairobi Kenya}

Most OFSP traders, $66.7 \%$, do not check temperature and humidity daily during transportation. About $68 \%$ of OFSP did control pests in their stores, and about $45 \%$ did not clean ether trucks and containers after and before transportation. The result reveals that most traders do not follow good distribution practice which may contribute to food contamination. See table 13.

Table 13: Frequency of scores on Food safety practices among OFSP traders

\begin{tabular}{llll}
\hline & Food Safety Practices Questions & $\begin{array}{l}\text { Appropriate } \\
\text { practice (\%) }\end{array}$ & $\begin{array}{l}\text { Inappropriate } \\
\text { practice }(\%)\end{array}$ \\
\hline 1 & Do you wash hands before handling products & 85.3 & 14.7 \\
2 & Do you observe good hygiene practices & 96.0 & 4.0 \\
3 & Do you the trucks and containers cleaned after and before transporting & 54.7 & 45.3 \\
4 & Temperatures in transporting track is checked & 22.7 & 77.3 \\
5 & Do you observe personal hygiene when handling products & 94.6 & 5.4 \\
6 & Do you inspect food in stock & 90.7 & 9.3 \\
7 & Do you check temperature and humidity daily & 33.3 & 66.7 \\
8 & Do you discard all expired food & 93.3 & 6.7 \\
9 & Do you store products above the ground & 77.0 & 23.0 \\
10 & Is your storage facility cleaned and maintained & 67.6 & 32.4 \\
11 & Are & 32.0 & 68.0 \\
12 & Do you record harvests date's & 38.7 & 61.3 \\
13 & Do you record type and amount of products loaded & 72.0 & 28.0 \\
14 & Do you record person driving the transport vehicles & 48.0 & 52.0 \\
\hline
\end{tabular}

\subsubsection{Correlation between Knowledge, Attitude and practices of OFSP traders}

The correlation between Food safety knowledge attitude and practice was determined in this study. Pearson's correlation analysis revealed a strong positive correlation between food safety attitude and food safety practice $\mathrm{p}=0.015$. Similarly existed a strong positive correlation between food safety practice and food safety knowledge $\mathrm{p}<0.001$. See table 14 .

Table 14: Correlation between Knowledge, Attitude and practices of OFSP traders

\begin{tabular}{lll} 
Level & Pearson correlation (r) & p-values \\
\hline Knowledge - Attitude & 0.087 & 0.887 \\
Attitude - practice & 0.286 & $0.015^{*}$ \\
practices - Knowledge & 0.771 & $0.000^{*}$
\end{tabular}

*Correlation significant at 0.05 level (2 tailed)

3.2.8 Effect of food safety knowledge and attitude on food safety practices

Adjusted linear regression was used to assess the effect of food safety knowledge and attitude on food safety practices. Results revealed that food safety practice was significantly impacted by both knowledge and attitude 
$\mathrm{R} 2=0.578 \mathrm{~F}=49.6 \mathrm{p}=0.000$. See table 15 .

Table 15: Adjusted linear regression assessing the effect of food safety knowledge and attitude on food safety practices

\begin{tabular}{llll} 
Variables & Coefficient & Std. Error & p-value \\
\hline Knowledge & 0.713 & 0.067 & 0.000 \\
Attitude & 0.291 & 0.073 & 0.000 \\
& & $\mathrm{R}^{2}=0.578 \mathrm{~F}=49.6 \mathrm{p}=0.000$ & \\
\hline
\end{tabular}

Variables significant at 0.05 (2 tailed)

\subsection{Orange Fleshed Sweet potato (OFSP) Street Food Consumers in Nairobi Kenya}

\subsubsection{Social demographic characteristics:}

The demographic characteristics of the respondents were analyzed. Out of 50 OFSP Street food consumers were recruited in the study, of which $40 \%$ were male, while $60 \%$ were female, with an age range spread between 13 to 65 years, with the majority $40 \%$ street OFSP consumers being between ages range of 25-34 years. About 30\% of the respondents had primary education, and most respondents (6\% attained secondary and 24\%) tertiary education. See table 16.

Table 16: Social Demographic Characteristics of OFSP Street Food Consumers $(\mathbf{N}=50)$

\begin{tabular}{llll} 
Social demographic Variables & & Frequency $(\mathrm{n})$ & Percentage $(\%)$ \\
\hline Gender & Males & 20 & 40.0 \\
& Females & 30 & 60.0 \\
\hline Age (Years) & $13-17$ & 1 & 2.0 \\
& $18-24$ & 12 & 24.0 \\
& $25-34$ & 20 & 40.0 \\
& $35-44$ & 6 & 12.0 \\
& $45-54$ & 7 & 14.0 \\
& $55-64$ & 3 & 6.0 \\
Education level & 65 Years+ & 1 & 2.0 \\
& Primary & 15 & 30.0 \\
Main occupation & Secondary & 23 & 46.0 \\
& Tertiary & 12 & 24.0 \\
& Unemployed & 5 & 10.0 \\
& Full time employed & 9 & 18.0 \\
& Part time employed & 4 & 8.0 \\
& Self employed & 25 & 50 \\
& Others & 7 & 14.0
\end{tabular}

3.3.2 Food Safety Knowledge, Attitude and Practices (KAP) overall, among OFSP street food consumers The results reveal a mean percentage scores OFSP food safety consumers knowledge at $66.2 \%$, which is below the cut-off point most street consumers did not have sufficient knowledge about food safety hygiene practices which could lead to serious foodborne illnesses. The mean percentage scores OFSP among OFSP Street consumers seem to be very positive at $87.3 \%$, and the food safety practices among OFSP consumers seem to be appropriate $91.6 \%$. The overall food safety knowledge, attitude and practice among OFSP street consumers were very good. The mean percentage scores For Safe Food Safety Knowledge, Attitude and Practice of OFSP Street Consumers See figure 3.

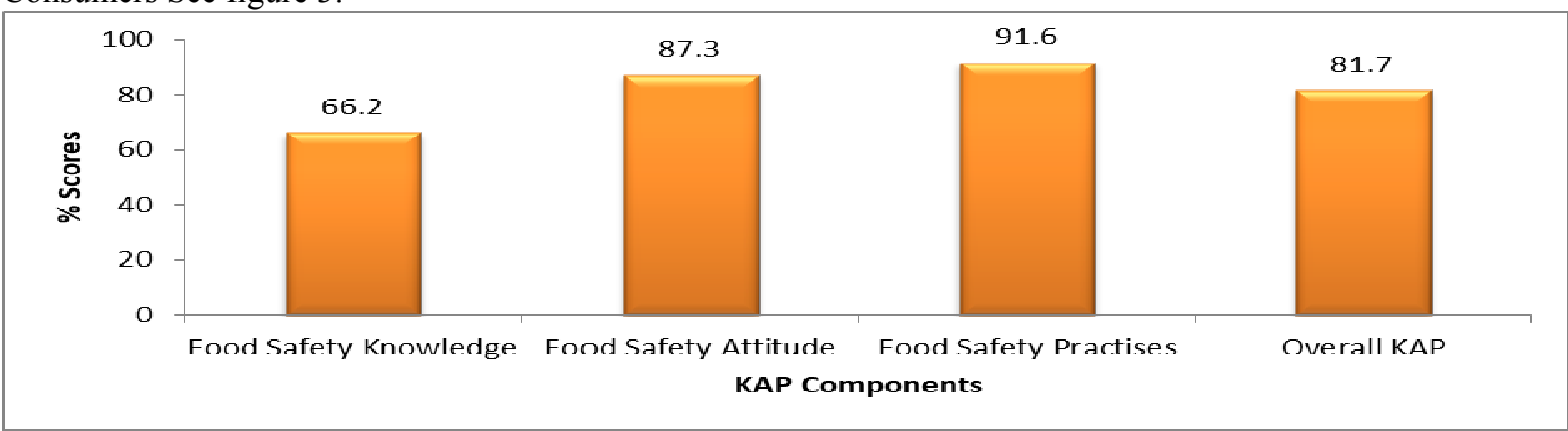

Figure 3: Mean percentage scores For Safe Food Safety Knowledge, Attitude and Practice among OFSP street consumers

3.3.3 Association between sociodemographic characteristics and Food safety KAP among OFSP street consumers

Socio-demographic characteristics were compared with food safety KAP overall; the results revealed that lower 
education level, was statistically significantly associated with inappropriate practices among OFSP street consumers $p=0.040$. Other socio-demographic characteristics factors were not statistically significantly associated with food safety KAP overall among OFSP street consumers. See table 17.

Table 17: Means Scores: Food Safety Knowledge, Attitude, Practices and Overall KAP of OFSP Street Food Consumers as per demographic characteristics by ANOVA and Test

\begin{tabular}{|c|c|c|c|c|c|c|c|c|c|}
\hline \multirow{2}{*}{$\begin{array}{l}\text { Demographic } \\
\text { variable }\end{array}$} & & \multirow[t]{2}{*}{$\mathrm{N}$} & \multicolumn{2}{|l|}{ Knowledge } & \multicolumn{2}{|l|}{ Attitude } & \multicolumn{2}{|l|}{ Practices } & \multirow{2}{*}{$\begin{array}{l}\text { Overall KAP } \\
\text { Mean } \pm \text { SD }\end{array}$} \\
\hline & & & Mean \pm SD & $\begin{array}{l}\mathrm{p}- \\
\text { value }\end{array}$ & Mean \pm SD & $\begin{array}{l}\mathrm{p}- \\
\text { value }\end{array}$ & Mean \pm SD & $\begin{array}{l}\mathrm{p}- \\
\text { value }\end{array}$ & \\
\hline \multirow[t]{2}{*}{ Gender } & Males & 20 & $63.7 \pm 16.1$ & 0.313 & $89.3 \pm 7.9$ & 0.239 & $92.6 \pm 7.2$ & 0.566 & $81.6 \pm 15.8$ \\
\hline & Females & 30 & $67.8 \pm 11.7$ & & $86.0 \pm 10.6$ & & $91.0 \pm 11.4$ & & $81.7 \pm 12.3$ \\
\hline \multirow[t]{5}{*}{ Age (Years) } & $13-17$ & 1 & 70.0 & & 66.6 & & 84.6 & & $73.7 \pm 9.5$ \\
\hline & $18-24$ & 12 & $63.7 \pm 18.3$ & & $86.1 \pm 9.6$ & & $94.8 \pm 5.9$ & & $81.5 \pm 16.0$ \\
\hline & $25-34$ & 20 & $68.0 \pm 12.2$ & 0.439 & $89.3 \pm 8.4$ & 0.993 & $92.3 \pm 9.3$ & 0.233 & $83.2 \pm 13.2$ \\
\hline & $35-44$ & 6 & $75.0 \pm 5.4$ & & $91.1 \pm 10.0$ & & $96.1 \pm 6.4$ & & $87.4 \pm 11.0$ \\
\hline & $55-64$ & 3 & $65.0 \pm 8.6$ & & $86.6 \pm 17.6$ & & $82.0 \pm 11.7$ & & $77.8 \pm 11.3$ \\
\hline Primary & & 15 & $63.0 \pm 14.3$ & 0.499 & $84.0 \pm 10.3$ & 0.212 & $87.1 \pm 12.2$ & 0.040 & $78.0 \pm 13.1$ \\
\hline Secondary & & 23 & $68.4 \pm 12.2$ & & $87.8 \pm 8$ & & $91.9 \pm 9.1$ & & $82.7 \pm 12.6$ \\
\hline Tertiary & & 12 & $65.8 \pm 16.3$ & & $90.5 \pm 6.00$ & & $96.8 \pm 5.4$ & & $84.4 \pm 16.3$ \\
\hline Mean & & & $67.04 \pm 3.6$ & & $85.73 \pm 7.1$ & & $90.92 \pm 4.9$ & & $80.8 \pm 3.9$ \\
\hline
\end{tabular}

3.3.4 Food safety knowledge among OFSP Street consumers

The knowledge of OFSP was assessed, and the results reveal that most of the OFSP street consumers' have knowledge on food hygiene. About $84 \%$ of the respondents have purchased orange-fleshed sweet potato on the streets and believe that OFSP is a nutritious crop and a good source of various nutrients. About $72 \%$ of the OFSP consumer believes that consuming the OFSP is good for children and the elderly and can reduce nutritional deficiencies in women and children. However, $28 \%$ of the consumers believe that street vendors do not adhere to hygiene principles. About 30 of consumers do not know that paper/polythene packs are unsafe for food packaging. See table 18 .

Table 18: Food Safety Knowledge responses by OFSP Street consumers $(n=50)$

$$
\text { Food Safety Question }
$$

2 Have you tasted Orange Fleshed Sweet Potatoes?

Have you ever purchased Orange fleshed sweet potatoes from street vendors?

4 Do you think the food vendors prepare and sell food adhering to hygiene principles?

$5 \quad$ Which type of sweet potatoes help with good eyes right?

6 Orange fleshed sweet potato is a good source of energy

7 Orange fleshed sweet potatoes is a good food for children and the elderly

8 Orange fleshed sweet potatoes is a good source of fiber, this helps prevent constipation.

9 Consuming orange fleshed sweet potatoes regularly can reduce nutritional 72.0 deficiencies in women and children

10 Which potatoes have least fat?

11 Do you feed your children with orange fleshed sweet potatoes?

12 Washing hands properly reduces risk of food contamination

13 Use of gloves reduces the risk of transmitting infection to consumers

14 Contaminated foods always have some change in color, odor or taste

15 paper/polythene packs are unsafe for food packaging

16 Consuming contaminated food can cause foodborne illnesses?

17 Practicing food hygiene is everyone's responsibilities?

18 How often do you buy food/snack/items/drinks from vendors/street sellers?

19 What time of the day do you usually buy food/snack items/drinks from vendors/street sellers?

20 Where do you usually buy your breakfast/snack/lunch from vendors/street 92.0

\begin{tabular}{ll}
$\begin{array}{l}\text { With } \\
\text { Knowledge } \\
(\%)\end{array}$ & $\begin{array}{l}\text { Without } \\
\text { Knowledge } \\
(\%)\end{array}$ \\
\hline 88.0 & 12.0 \\
94.0 & 6.0 \\
84.0 & 16.0 \\
72.0 & 28.0 \\
64.0 & 36 \\
90.0 & 10 \\
84.0 & 16.0 \\
80.0 & 20.
\end{tabular}

$80.0 \quad 20$.
sellers?

\subsubsection{Food Safety Attitude among OFSP Street Food Consumers}

The food safety attitude among OFSP Street Food Consumers was assessed. The results revealed that about $98 \%$ 
of OFSP Street food consumers have positive food safety attitude and observant about hygiene practices before buying food from any street vendor. All 100\% interviewed OFSP were positive and knew that Good personal hygiene could prevent foodborne illnesses. About $96 \%$ of the respondents know that foodborne illnesses can have deleterious health and economic effects on society. However, about $30 \%$ of the consumers did not believe that using gloves is important in reducing the risk of food contamination, and $46 \%$ of the respondents did not believe that protective clothing can reduce the risk of food contamination. See table 19.

Table 19: Food Safety attitude responses by OFSP Street Food Consumers $(\mathbf{N}=50)$

Statement on food safety Attitude

$1 \quad$ I always observe hygiene practice before buying food from any street vendor

2 Food safety knowledge will benefit personal life

3 Food safety Knowledge will be of benefit to consumers

4 Safe food handling is important and is everyone's' responsibility

5 Good personal hygiene can prevent foodborne illnesses

$6 \quad$ Washing hands before handling food reduces risk of food poisoning

7 Producing safe food is more important than tasty food

8 You are satisfied with hygiene practices where you buy food

9 Food should not be touched with wounded hands

10 Using gloves is important in reducing the risk of food contamination

11 Protective clothing reduces the risk of food contamination

12 Foodborne illnesses can have deleterious health and economic effects on the society

13 Food hygiene training for workers is an important issue in reducing risk of food contamination

14 Well cooked food is free of contamination

15 Raw and cooked foods should be stored separately to reduce the risk of food 96.0 contamination

\begin{tabular}{ll}
$\begin{array}{l}\text { Positive } \\
\text { Attitude } \\
(\%)\end{array}$ & $\begin{array}{l}\text { Negative } \\
\text { Attitude } \\
(\%)\end{array}$ \\
\hline 98.0 & 2.0 \\
94.0 & 6.0 \\
100.0 & 0.0 \\
94.0 & 6.0 \\
100.0 & 0.0 \\
84.0 & 16.0 \\
86.0 & 14.0 \\
78.0 & 22.0 \\
86.0 & 14.0 \\
70.0 & 30.0 \\
54.0 & 46.0 \\
96.0 & 4.0 \\
98.0 & 2.0 \\
76.0 & 24.0 \\
96.0 & 4.0
\end{tabular}

\subsubsection{Food Safety practice among OFSP Street Food Consumers}

Food safety practice among OFSP street consumer was assessed, and the results reveal that the consumers are knowledgeable about food safety practices. About $98 \%$ of OFSP believe that a clean vendor can prevent food contamination. All 100\% of the OFSP consumers believe that washing hands before eating food is a good practice to avoid food contamination. However, $18 \%$ of the OFSP street consumer had an inappropriate practice of not washing hands before and after touching unwrapped raw foods. This percent is too high to cause food contamination, resulting in an outbreak of food-borne diseases. See table 20.

Table 20: Frequency of scores on Food safety Practices

\begin{tabular}{|l|l|l|l|}
\hline & Food Safety Practices Questions & $\begin{array}{l}\text { Appropriate } \\
\text { Practice (\%) }\end{array}$ & $\begin{array}{l}\text { Inappropriate } \\
\text { practice (\%) }\end{array}$ \\
\hline $\mathbf{1}$ & A clean vendor can prevent food contamination & 98.0 & 2.0 \\
\hline $\mathbf{2}$ & Washing hands before eating food & 100.0 & 0.0 \\
\hline $\mathbf{3}$ & Washing hands before touching unwrapped raw foods. & 80.0 & 18.0 \\
\hline $\mathbf{4}$ & Washing hands after touching unwrapped raw foods & 82.0 & 18.0 \\
\hline $\mathbf{5}$ & Using soap/detergents to wash hands & 96.0 & 4.0 \\
\hline $\mathbf{6}$ & Washing hands after touching prepared food & 96.0 & 4.0 \\
\hline $\mathbf{7}$ & Cleaning the utensils for use during eating & 96.0 & 4.0 \\
\hline $\mathbf{8}$ & Washing hands after using the washroom & 100.0 & 0.0 \\
\hline $\mathbf{9}$ & Using tissue/cloth when coughing or sneezing & 88.0 & 12.0 \\
\hline $\mathbf{1 0}$ & Using detergent to clean equipment & 94.0 & 6.0 \\
\hline $\mathbf{1 1}$ & Drying equipment before use & 86.0 & 14.0 \\
\hline $\mathbf{1 2}$ & Rubbing hands on face, hair, etc. while eating & 74.0 & 26.0 \\
\hline $\mathbf{1 3}$ & Smoking in the workplace & 98.0 & 2.0 \\
\hline $\mathbf{3}$ & Correlatin ans & \\
\hline
\end{tabular}

\subsubsection{Correlation among Knowledge, Attitude and Practices of OFSP street consumers}

The correlation between food safety practice and knowledge was determined in this study. Pearson's correlation analysis revealed a positive weak correlation between food safety knowledge and food safety attitude $\mathrm{p}=0.332$. Similarly, a positive weak correlation was found between food safety attitude and food safety $p=0.197$. There was also a positive weak correlation between food safety practice and food safety knowledge $p=0.186$. See table 21. 
Table 21: Correlation among Knowledge, Attitude and Practices of OFSP street consumers

Level Pearson correlation $(r)$

Knowledge - Attitude

0.140 p-values

Attitude - Practice

0.186

0.332

practices - Knowledge

0.190

0.197

*Correlation significant at 0.05 level ( 2 tailed)

3.3. 8 Effect of food safety knowledge and attitude on food safety practices

Adjusted linear regression was used to assess the effect of food safety knowledge and attitude on food safety practices. Results revealed that Food safety knowledge and attitude had no statistically significant effect on practice $\mathrm{R} 2=0.062 \mathrm{~F}=1.55 \mathrm{p}=0.222$. See table 22 .

Table 22: Adjusted linear regression assessing the effect of food safety knowledge and attitude on food safety practices

\begin{tabular}{llll} 
Variables & Coefficient & Std. Error & p-value \\
\hline Knowledge & 0.168 & 0.070 & 0.246 \\
Attitude & 0.162 & 0.133 & 0.261 \\
& & $\mathrm{R}^{2}=0.062 \mathrm{~F}=1.55 \mathrm{p}=0.222$ &
\end{tabular}

Variables significant at 0.05 ( 2 tailed)

\section{Discussion}

The results of this study revealed a big gap in food safety Knowledge attitude and practices dynamics across agri-foods value chains. Among the OFSP processors results revealed a fairly good food safety KAP with overall mean percentage score of $84.6 \%$. The factor that was associated with food safety KAP was the education level which was statistically significantly associated with poor food safety practice among OFSP processors. This results compares well with the study by (Tuglo et al., 2021) in North Dayi District, Ghana, who found that among street-cooked food handlers in Ghana, the food handlers with secondary education were 4 times good at hygiene practices of food safety likened to no education $[\mathrm{aOR}=4.06, \mathrm{p}=0.003]$. Another study in Kenya by (Malavi, 2017) also found the overall mean percentage scores of $81 \%$ for knowledge, attitude, practices and overall KAP. The training among OFSP processors had a significant impact on knowledge $(\mathrm{p}=0.020)$, attitude $(\mathrm{p}=0.050)$, practices $(\mathrm{p}=0.006)$ and overall KAP $(\mathrm{p}=0.001)$. A study by (omar, 2020) found fairly good levels of KAP of food safety with overall KAP at 79.13\% among food handlers, specifically during COVID-19 the food handlers were practicing good hygienic practices. Another study in Ghana by (Akabanda et al., 2017) found that food-handlers were knowledgeable about hygienic practices, cleaning and sanitation procedures. Almost all of the food-handlers were aware of the critical role of general sanitary practices in the workplace. A study by Ncube et al., 2020 determined the food safety knowledge, attitudes, and self-reported and observed practices of food handlers in 22 urban restaurants in Zimbabwe. Results indicated that food safety knowledge scores were significantly higher in food handlers who received basic food safety training compared to those who did not ( $p$ $<.05)$. No differences in food safety knowledge and attitudes were noted based on the socio-demographic characteristics of the food handlers $(p>.05)$.

Traders food safety knowledge attitude and practice among the OFSP traders was assessed in this study, results revealed an overall food safety KAP among OFSP traders was 67.4 which is below the cut-off point. This could be contributed by many factors, including lack of awareness about food safety on transportation regulation and lack for enforcement of the laws available for transportation. These results compare well with other study done among traders. A study done in Brazil by (Auad et al., 2019), determined food safety knowledge, attitudes, and practices among Brazilian Food Truck Handlers. Results of the reveal that, food truck handlers were likely to exhibit food contamination and are at a high risk of foodborne diseases; the results suggests that, understand food handlers' point of view is the initial diagnosis to guide educational strategies in the food truck sector.

Food safety Knowledge, attitude and practice was assessed among OFSP street consumers, results revealed an overall mean score KAP of $81.7 \%$ which is equally good. Although the overall mean score is good, still there are some aspects of food hygiene practices that are not appropriately done and need to be addressed. This is due to the fact that food safety issues are very sensitive and a small percentage of contamination in food can result to huge outbreak of foodborne illnesses. These results are comparable to other studies conducted among the consumers. A study by (Hossen et al., 2021) evaluated food safety knowledge, attitude and practice (KAP) among food vendors in Bangladesh. Results revealed that, while 72.5\% vendors had good knowledge of food safety, only $33 \%$ and $0.5 \%$ had good food safety attitude and practice, respectively. Over $90 \%$ vendors did not use any personal protective equipment, $4.5 \%$ had diarrhea, $8.5 \%$ did not wash their hands after going to the toilet and $28.5 \%$ reused previous leftover oils. Level of education showed significant influence $(\mathrm{p}=0.005$ and 0.015$)$ on the food safety knowledge and practice of the vendors. Another study by (Le Nguyen et al., 2018) explored the knowledge, attitude, and practices (KAP) of customers regarding the practices of food facilities as well as potential associated factors; Results revealed that the highest mean score of $98.4(\mathrm{SD}=10.1)$ was found in 
knowledge, however most of customers considered the processing and selling of hygienic meals without leaving any food overnight as the most important feature for food facilities $(73.8 \%)$ and about $63.2 \%$ of participants chose not to report food safety violation by facilities to authorities.

\section{Conclusion}

This study reveals a gap in food safety knowledge, attitude, and practice in the food value chain. These findings call for authorities to act and strengthen food safety systems by training human resources, improving infrastructures for better operations, food safety culture, and enforcement of laws and regulations of food safety. Supervisions and follow-ups are also important to encourage positive behavior among food handler traders and consumers to improve food hygiene status; this is important because people sometimes may possess knowledge but do not translate into strictly hygienic practices during handling food products. Adequate guidelines should be provided to improve food safety practices, and reduce the growing food borne illnesses.

\section{References}

Akabanda, F., Hlortsi, E.H., Owusu-Kwarteng, J. (2017). Food safety knowledge, attitudes and practices of institutional food-handlers in Ghana. BMC Public Health, 17, 1-9. https://doi.org/10.1186/s12889-0163986-9.

Auad, L.I., Ginani, V.C., Stedefeldt, E., Nakano, E.Y., Nunes, A.C.S., Zandonadi, R.P. (2019). Food safety knowledge, attitudes, and practices of brazilian food truck food handlers". Nutrients 11. https://doi.org/10.3390/nu11081784.

Bendekovic, J., Naletina, D., Nola, I. (2018). Food Safety and Food Quality in the Supply, 1-13.

Fariba, R., Gholamreza, J.K., Saharnaz, N., Ehsan, H., Masoud, Y. (2018). Knowledge, attitude, and practice among food handlers of semi-industrial catering: A cross sectional study at one of the governmental organization in Tehran. J. Environ. Heal. Sci. Eng. 16, 249-256. https://doi.org/10.1007/s40201-018-03128.

GFSP, (2019). Food Safety in Africa. Past Endeavors and Future Directions Global Food Safety Partnership 1-6. Grace, D. (2015). Food safety in developing countries: an overview. Glob. Food Sec. 4, 24-29.

Hossen, M.T., Ferdaus, M.J., Hasan, M.M., Lina, N.N., Das, A.K., Barman, S.K., Paul, D.K., Roy, R.K. (2021). Food safety knowledge, attitudes and practices of street food vendors in jashore region, bangladesh. Food Sci. Technol. 41, 226-239. https://doi.org/10.1590/fst.13320.

Jubayer, M.F., Kayshar, M.S., Hossain, M.S., Uddin, M.N., Al-Emran, M., Akter, S.S. (2020). Evaluation of food safety knowledge, attitude, and self-reported practices of trained and newly recruited untrained workers of two baking industries in Dhaka, Bangladesh. Heliyon 6, e05021. https://doi.org/10.1016/j.heliyon.2020.e05021.

Le Nguyen, A.T., Tran, B.X., Le, H.T., Le, X.T.T., Do, K.N., Do, H.T., Vu, G.T., Nguyen, L.H., Latkin, C.A., Ho, C.S.H., Ho, R.C.M. (2018). Customers' knowledge, attitude, and practices towards food hygiene and safety standards of handlers in food facilities in Hanoi, Vietnam. Int. J. Environ. Res. Public Health 15. https://doi.org/10.3390/ijerph15102101.

Malavi, D.N. (2017). Food Safety Knowledge, Attitude and Practices of Orange-Fleshed Sweetpotato Puree handlers in Kenya. Food Sci. Qual. Manag. 67, 54-63.

Marais, M., Conradie, N., Labadarios, D. (2007). Small and micro enterprises - Aspects of knowledge, attitudes and practices of manager's and food handlers' knowledge of food safety in the proximity of Tygerberg Academic Hospital, Western Cape. South African J. Clin. Nutr. 20, 50-61. https://doi.org/10.1080/16070658.2007.11734124.

Ncube, F., Kanda, A., Chijokwe, M., Mabaya, G., Nyamugure, T. (2020). Food safety knowledge, attitudes and practices of restaurant food handlers in a lower-middle-income country. Food Sci. Nutr. 8, 1677-1687. https://doi.org/10.1002/fsn3.1454.

Oloo, J. (2011). Food safety and quality management in Kenya: An overview of the roles played by various stakeholders. African J. Food, Agric. Nutr. Dev. 10. https://doi.org/10.4314/ajfand.v10i11.64283.

omar, sharaf. (2020). Hygienic Food Practice among Food Workers in Jordanian Food Factories during pandemic crisis: COVID-19:comparative study 1-14. https://doi.org/10.21203/rs.3.rs-29784/v1

Todd, E. (2020). Food-borne disease prevention and risk assessment. Int. J. Environ. Res. Public Health 17, 113. https://doi.org/10.3390/ijerph17145129.

Tuglo, L.S., Agordoh, P.D., Tekpor, D., Pan, Z., Agbanyo, G., Chu, M. (2021). Food safety knowledge, attitude, and hygiene practices of street-cooked food handlers in North Dayi District, Ghana. Environ. Health Prev. Med. 26, 1-13. https://doi.org/10.1186/s12199-021-00975-9.

WHO. (2015). Food-Borne Disease Burden Epidemiology Reference Group. Encycl. Parasitol. 1-1. https://doi.org/10.1007/978-3-642-27769-6 3884-1.

WHO. (1999). Strategies for Implementing HACCP in Small and/or Less Developed Businesses: Report of a 
WHO Consultation WHO/SDE/PH, 1-33.

Yen, E., Hoffman, V., Grace, D., Karugia, J. (2018). Food safety in Kenya: Focus on fruits and vegetables 1-4. 